\section{Discussion of "Skimming, Nonaerated Flow on Stepped Spillways over Roller Compacted Concrete Dams" by Inês Meireles, Floriana Renna, Jorge Matos, and Fabián Bombardelli}

DOI: 10.1061/(ASCE)HY.1943-7900.0000591

\author{
Michael Pfister ${ }^{1}$ and Robert M. Boes ${ }^{2}$ \\ ${ }^{1}$ Research and Teaching Associate, Laboratory of Hydraulic Constructions \\ (LCH), Ecole Polytechnique Fédérale de Lausanne (EPFL), CH-1015 \\ Lausanne, Switzerland (corresponding author). E-mail: michael \\ .pfister@epfl.ch \\ ${ }^{2}$ Professor and Director, Laboratory of Hydraulics, Hydrology and \\ Glaciology (VAW), ETH Zurich, CH-8092 Zürich, Switzerland. \\ E-mail: boes@vaw.baug.ethz.ch
}

The discussers read the paper with interest and congratulate the authors for their excellent contribution. It is relevant to focus on the flow characteristics upstream of the self-inception point, as practice tends to design stepped spillways for increased specific discharges. The discussers add some aspects in this context, focusing on differences between their research (Boes 2000; Pfister 2002) and that of the authors.

\section{Flow at Inception Point}

Boes and Hager (2003) define the inception point where the bottom air concentration is $C_{b}=0.01$. Rearranging their equations for the related location and black water depth yields

$$
\begin{aligned}
& \frac{L_{i}}{k}=6.67 \mathrm{~F}^{* 0.80} \\
& \frac{d_{i}}{k}=0.33 \mathrm{~F}^{* 0.60}
\end{aligned}
$$

Considering the range of the authors' experiments up to $\mathrm{F}^{*}=$ $q_{w} /\left(g \sin \theta k^{3}\right)^{0.5} \approx 54$, the maximum deviation of the authors' Eqs. (1) and (2) from these Eqs. (1) and (2) is $15 \%$ for $L_{i} / k$ and $5 \%$ for $d_{i} / k$, respectively. The agreement between the authors' results and those of Boes and Hager (2003) also holds true for the depth-averaged air concentration at the inception point, which deviates by only $(0.224-0.203) / 0.203=0.103=10.3 \%$. Regarding the difficulties in defining the inception point location in high-speed two-phase flow, the agreement is considered good, also corroborating the definition of Boes and Hager (2003).

When increasing the unit discharge on stepped spillways, cavitation damage becomes a concern. Amador et al. (2009) noted that critical negative dynamic pressures linked to possible cavitation formation occur near the inception point if the unit discharge $q>15 \mathrm{~m}^{2} / \mathrm{s}$. If computing the cavitation index $\sigma$ according to Falvey (1990), based on "average hydraulics" instead of effective local pressures, values as shown in Fig. 1 result at the inception point for $\theta=50^{\circ}$ and two common step heights of $h=0.3$ and $1.2 \mathrm{~m}$. Based on the limiting discharge of $15 \mathrm{~m}^{2} / \mathrm{s}$ of Amador et al. (2009), the critical cavitation index becomes $\sigma_{c}=0.5$ and 0.7 (Fig. 1), i.e., above the critical value of $\sigma_{c}=0.2$ for smooth chutes. Frizell and Renna (2011) report $\sigma_{c}=0.6-0.7$ for mild-sloping stepped spillways and reduced atmospheric pressure if considering the pseudobottom as reference, whereas $\sigma_{c} \cong 1.3$ at the step edge. The latter acts as a macroroughness element slightly protruding into the skimming flow because the pseudobottom does not precisely describe the effective streamlines. This concept might be combined with the observations of Falvey (1990), who reports $\sigma_{c}=0.5-1.5$ for into-the-flow chamfers, if the angle of attack is equal to pseudobottom versus the horizontal step face $1 / \tan \theta=0.84$. Boes (2012) recommends considering $\sigma_{c}=0.5$ for stepped spillways up to $\theta=55^{\circ}$. Frizell et al. (2012) were the first to conduct model tests relating to cavitation on stepped spillways, using a low ambient pressure and acoustic emission technology. Based on Arndt and Ippen (1968), they proposed $\sigma_{c}=4 f$, with $f$ as friction factor. For the tested set-ups, they found $\sigma_{c}=0.3-0.6$. The first stepped spillway bottom aerators to counter cavitation were presented by Pfister et al. (2006) and Schiess et al. (2008).

\section{Flow Upstream of Inception Point}

The values of the streamwise depth-averaged mean air concentration $C_{\text {mean }}$ upstream of the inception point are described by the authors as $C_{\text {mean }}=0.14$ along $0.25<L / L_{i}<0.75$. The data of the discussers provide slightly smaller values tending to $C_{\text {mean }} \rightarrow 0$ at roughly $L / L_{i}<0.4$ [Fig. 2(a)]. Although the discussers have less data than the authors, this trend seems reasonable. Surface troughs or waves are small at the upper end of a stepped spillway (Pfister and Hager 2011), as visible in Fig. 2(b), showing the model of Pfister (2002). In the upper reach, $C_{\text {mean }}$ values are sensitive to the measurement grid space near the flow surface. A comparison of selected parameters of the three mentioned studies is given in Table 1.

The flow surface $Y_{90}$ is commonly defined along the concentration line $C=0.90$ and the black water depth as $d=$ $Y_{90}\left(1-C_{\text {mean }}\right)$. As an alternative, $Y_{95}$ along the concentration line $C=0.95$ might be used, or even $Y_{99}$ along $C=0.99$. Similar to the authors, Boes (2000) observed $Y_{99 i} / d_{i}>1.6$ at the inception point. The data of Pfister (2002) shown in Fig. 3(a) indicate $Y_{90 i} / d_{i} \approx$ 1.25 and $Y_{95 i} / d_{i} \approx 1.35$. These values are marginally higher than those of the authors, related to the "rougher" stepped spillway (in terms of roughness height $k$ ) of Pfister (2002) (Table 1).

As for the kinetic energy correction coefficient $\alpha$, the authors propose $\alpha=1.19$ at $L / L_{i}=1$, in agreement with $\alpha=1.15$ from Chanson (1994) using

$$
\alpha=\frac{(N+1)^{3}}{(N+3) N^{2}}
$$

and based on $N=3.4$. Boes (2000) observed values on the order of $1.05 \leq \alpha \leq 1.10$ downstream of the inception point, with few values $\alpha>1.10$. Pfister (2002) derived individual values $N$ with a curve-fitting procedure and then computed $\alpha$ based on Eq. (3). The resulting values are shown in Fig. 3(b), indicating values below the authors' proposal but in accordance with Boes (2000). Given the turbulent flow near the inception point, "steep" velocity profiles with small values of $\alpha$ are likely. Steep velocity profiles with $1.0<$ $\alpha \leq 1.05$ were observed by VAW (2013) also in the fully aerated uniform flow region of a $1: 2(V: H)\left(\theta=26.6^{\circ}\right)$ sloping stepped spillway. These findings hold true both for $\alpha$ values from Eq. (3) based on a curve-fitting procedure to determine $N$ in analogy to Pfister (2002) and from 


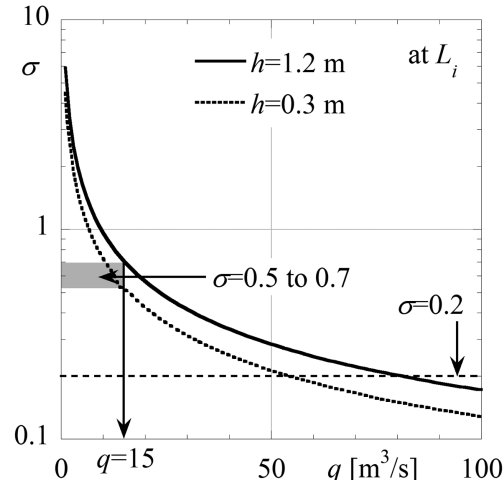

Fig. 1. Cavitation index $\sigma$ at inception point versus unit discharge $q$ for two common step heights $h$

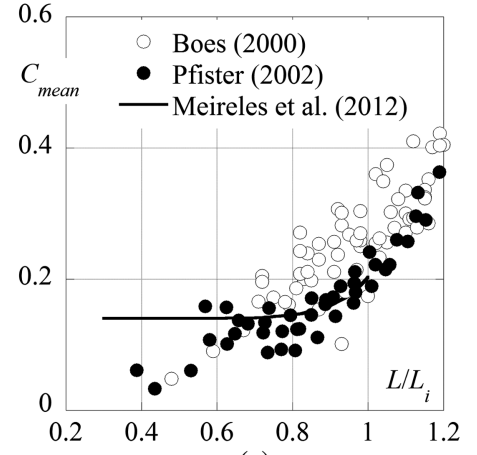

(a)

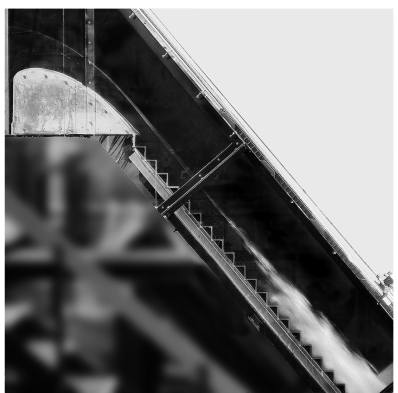

(b)
Fig. 2. (a) $C_{\text {mean }}$ versus small values of $L / L_{i}$; (b) physical model showing smooth flow surface along upper portion of stepped spillway (Pfister 2002)

Table 1. Limitations of Individual Studies

\begin{tabular}{lcccc}
\hline Study & $\theta\left(^{\circ}\right)$ & $h(\mathrm{~m})$ & $d_{c} / h(-)$ & Inflow type \\
\hline Boes (2000) & $30-50$ & $0.031-0.093$ & $0.8-10.5$ & Jet box \\
Pfister (2002) & 50 & 0.093 & $1.1-3.8$ & Ogee [Fig. 2(b)] \\
$\begin{array}{l}\text { Meireles et al. } \\
\text { (2012) }\end{array}$ & 53 & $0.040-0.080$ & $1.1-8.0$ & $\begin{array}{c}\text { Ogee, increasing } \\
\text { initial step heights }\end{array}$ \\
\hline
\end{tabular}

$$
\alpha=1+\frac{3}{u^{2} Y_{90}} \int_{0}^{Y_{90}} \Delta u^{2} \mathrm{~d} Y
$$

where $u=$ depth-averaged air-water mixture velocity and $\Delta u=$ difference between local and depth-averaged air-water mixture velocity. Note that the $\alpha$ values of VAW (2013) from Eqs. (3) and (4) have a maximum deviation of less than $2 \%$ and a mean deviation of about $1 \%$.
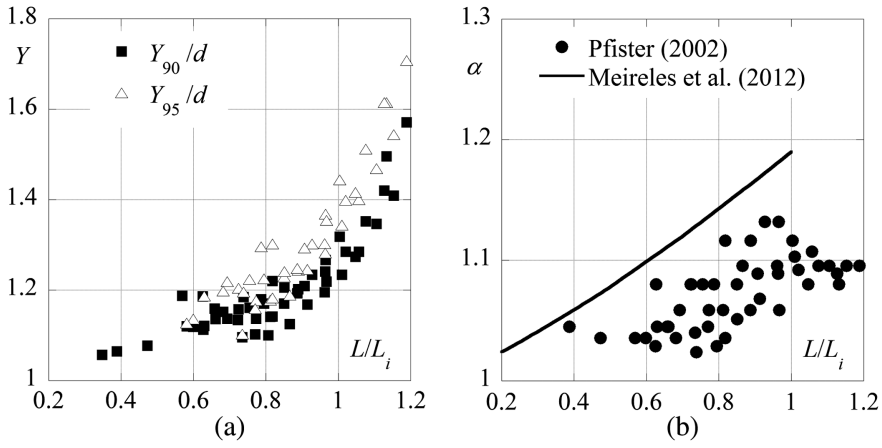

Fig. 3. (a) Relative flow depths $Y / d\left(L / L_{i}\right)$ defined up to different $C$; (b) $\alpha\left(L / L_{i}\right)$

\section{References}

Amador, A., Sánchez-Juny, M., and Dolz, J. (2009). "Developing flow region and pressure fluctuations on steeply sloping stepped spillways.” J. Hydraul. Eng., 10.1061/(ASCE)HY.1943-7900.0000118, $1092-1100$.

Arndt, R. E. A., and Ippen, A. T. (1968). "Rough surface effects on cavitation inception.” J. Basic Eng., 90(3), 249-261.

Boes, R. (2000). "Two-phase flow and energy dissipation at cascades." H.-E. Minor, ed., VAW Mitteilung 166, ETH Zurich, Switzerland (in German).

Boes, R. M. (2012). "Guidelines on the design and hydraulic characteristics of stepped spillways." 24th ICOLD Congress, ICOLD, Paris, France, 203-220.

Boes, R. M., and Hager, W. H. (2003). "Two-phase flow characteristics of stepped spillways." J. Hydraul. Eng., 10.1061/(ASCE)0733-9429 (2003)129:9(661), 661-670.

Chanson, H. (1994). Hydraulic design of stepped cascades, channels, weirs and spillways, Pergamon, Oxford, U.K.

Falvey, H. T. (1990). "Cavitation in chutes and spillways." Engineering Monograph 42, U.S. Bureau of Reclamation, Denver, CO.

Frizell, K. W., and Renna, F. M. (2011). "Laboratory studies on the cavitation potential of stepped spillways." 34th IAHR World Congress, IAHR, Madrid, Spain, (CD-ROM)

Frizell, K. W., Renna, F. M., and Matos, J. (2012). "Cavitation potential of flow on stepped spillways." J. Hydraul. Eng., 10.1061/(ASCE)HY .1943-7900.0000715, 630-636.

Pfister, M. (2002). "Stepped spillway aerator: Physical model investigation." M.Sc. thesis, Versuchsanstalt für Wasserbau, Hydrologie und Glaziologie (VAW), ETH Zurich, Switzerland (in German).

Pfister, M., and Hager, W. H. (2011). "Self-entrainment of air on stepped spillways." Int. J. Multiphase Flow, 37(2), 99-107.

Pfister, M., Hager, W. H., and Minor, H.-E. (2006). "Bottom aeration of stepped spillways.” J. Hydraul. Eng., 10.1061/(ASCE)0733-9429 (2006)132:8(850), 850-853.

Schiess, A., Pfister, M., Hager, W. H., and Minor, H.-E. (2008). "Hydraulic performance of step aerator." J. Hydraul. Eng., 10.1061/(ASCE)07339429(2008)134:2(127), 127-134.

Versuchsanstalt für Wasserbau, Hydrologie und Glaziologie (Laboratory of Hydraulics, Hydrology and Glaciology) (VAW). (2013). "Trängslet dam stepped spillway: Physical model investigation." VAW Rep. 4305, ETH Zurich, Switzerland. 